\title{
Penciptaan DaminatilaFont untuk Penotasian Kendang dan Gamelan Sunda
}

\author{
Asep Saepudin ${ }^{1}$ \\ Jurusan Karawitan, Institut Seni Indonesia Yogyakarta
}

\begin{abstract}
ABSTRAK
Tulisan ini bertujuan menguraikan proses penciptaan DaminatilaFont untuk penotasian kendang dan gamelan Sunda. Penelitian dilakukan dengan observasi, perancangan, ujicoba, dan pembuatan program. Program yang telah berhasil dibuat ini diberi nama DaminatilaFont. Program ini dapat digunakan untuk menulis notasi kendang Sunda baik kendang Ketuk Tilu, Keurseus, Jaipongan, Kiliningan, Wayang Golek, Degung Kreasi, Degung Klasik, maupun Pencak Silat. DaminatilaFont bisa pula digunakan untuk menulis notasi daminatila gamelan Sunda. Font ini merupakan penyempurnaan dari font yang selama ini banyak digunakan dalam menulis notasi gamelan yaitu Kepatihan Pro, Anggit Sunda5, dan Consolas. Berdasarkan ujicoba, dapat disimpulkan bahwa DaminatilaFont menjadi solusi terbaik untuk penulisan notasi kendang dan gamelan dalam karawitan Sunda.
\end{abstract}

Kata kunci: DaminatilaFont, notasi kendang; musik Sunda

\begin{abstract}
Creation of DaminatilaFont for the Musical Notation of Sundanese Kendang and Gamelan. This paper aims to describe the process of creating DaminatilaFont for the musical notation of Sundanese kendang and gamelan. The research was carried out by doing the observation, designing, testing, and program making. The program that has been successfully created is DaminatilaFont. This program can be used to write the notations of Sundanese kendang either for kendang Ketuk Tilu, Keurseus, Jaipongan, Kiliningan, Wayang Golek, Degung Kreasi, Degung Klasik, or Pencak Silat. DaminatilaFont can also be used to write notations in the daminatila of Sundanese gamelan. This font is a refinement of the font that has been widely used in writing gamelan notations namely Kepatihan Pro, Anggit Sunda5, and Consolas. Based on the experiment, it can be concluded that DaminatilaFont is the best solution for writing the notations of kendang and gamelan in Sundanese music.
\end{abstract}

Keywords: DaminatilaFont, notation of Kendang; Sundanese music

\section{Pendahuluan}

Akulturasi budaya sebagai bagian dari pergaulan dunia yang tanpa batas, tidak hanya berpengaruh pada perkembangan dan popularitas seni-seni etnik, tapi juga berpengaruh terhadap cara-cara pentransmisian seni itu sendiri (Julia, 2016). Maka, notasi merupakan kebutuhan yang tidak bisa dihindarkan untuk pentransmisian terutama dalam pendidikan seni di seluruh Indonesia. Notasi musik merupakan bahasa dalam sebuah karya musik. Notasi digambarkan dengan simbol-simbol yang kemudian diartikan atau dinyatakan lewat sebuah permainan pada instrumen musik (Arief, 2016). Dalam dunia seni khususnya seni karawitan, notasi dapat digunakan dalam berbagai keperluan, antara lain sebagai alat pendokumentasian, penilaian

Alamat korespondensi: Jurusan Karawitan, FSP ISI Yogyakarta. Jln. Parangtritis KM. 6,5 Sewon, Yogyakarta. HP. +62 81227978377. E-mail: asepisiyogya@gmail.com. 
kinerja mahasiswa, maupun analisis musikal secara tekstual. Hampir di semua pusat kehidupan karawitan menggunakan dan mengembangkan sistem notasi untuk berbagai keperluan, baik untuk pendokumentasian maupun untuk media belajar, dan bahkan untuk penyajian karawitan (Rusdiyantoro, 2011). Notasi diperlukan untuk memberikan informasi musik atau alat interpretasi (Merriam, 1995). Notasi (balungan) adalah hasil abstraksi gending yang divisualkan dalam bentuk lambang musikal, baik berupa angka, grafis, huruf, atau tanda lainnya (Hastuti, Khafi izh, dan Syarifzh, 2016). Dalam kerja etnomusikologi, notasi digunakan untuk mentranskipsikan secara detail komposisi musik hasil penelitian di lapangan untuk diolah di laboratorium (Nettl, 1964). Notasi diperlukan pula untuk penulisan Laporan Tugas Akhir mahasiswa dalam menyelesaikan studinya oleh mahasiwa di berbagai Perguruan Tinggi Seni. Oleh karena itu, notasi sangat penting keberadaannya terutama bagi para akademisi di Perguruan Tinggi Seni guna kelancaran proses pembelajaran.

Meskipun sistem penulisan notasi dalam karawitan Sunda telah ada sejak lama, namun cara/teknik penulisan notasi khusunya untuk waditralinstrumen kendang umumnya masih dilakukan secara manual. Sistem penulisan notasi di pada program komputer belum memiliki font sendiri sesuai dengan kebutuhan yang dapat mempermudah proses penulisan notasi kendang. Sampai dengan saat ini, menotasikan kendang merupakan permasalahan bagi para mahasiswa dan peneliti karena rumit dan lamanya menotasikan kendang Sunda. Notasi masih merupakan kendala dalam pembelajaran (Gratia, Johar, \& Farady, 2015), padahal kemampuan dalam hal penotasian akan berpengaruh terhadap hasil proses belajar mengajar (Eka, 2017). Permasalahan ini dirasakan pula oleh para mahasiswa yang menempuh studi baik pada program sarjana maupun pascasarjana yang bersentuhan dengan notasi gamelan Sunda.

Berdasarkan permasalahan di atas, perlu dibuat terobosan baru agar penulisan notasi kendang dapat mudah dan cepat. Untuk mengatasi permasalahan tersebut, penulis mencoba merancang sendiri teknik penulisan notasi kendang dan gamelan
Sunda. Penulis merancang dan berhasil membuat sistem penotasian kendang Sunda. Font yang telah penulis buat ini diberi nama DaminatilaFont. Font ini dibuat dengan mengacu pada kebutuhan di lapangan sehingga hasilnya dapat bermanfaat bagi para mahasiswa, dosen, dan peneliti dalam menuliskan notasi kendang dan gamelan Sunda untuk proses pembelajaran. Pembelajaran musik dengan menggunakan notasi adalah metode pembelajaran yang sederhana dan sangat mudah bagi siapa saja yang ingin mengenal, memahami dan mempelajari musik (Novita et al., 2018). Maka, DaminatilaFont dibuat sangat lengkap, bukan hanya untuk notasi kendang saja, akan tetapi untuk notasi gamelan Sunda yakni notasi daminatila yang selama ini digunakan oleh para akademisi di di ISBI Bandung. DaminatilaFont menjadi solusi terbaik untuk mengatasi permasalahan teknik penulisan kendang dan gamelan dalam karawitan Sunda.

\section{Penulisan Notasi dalam Karawitan Sunda}

Dalam karawitan Sunda, notasi biasanya digunakan untuk menuliskan dua kegiatan besar yaitu untuk menuliskan notasi kendang Sunda dan untuk menuliskan notasi gamelan. Notasi untuk penulisan kendang Sunda sudah dilakukan sejak lama oleh para akademisi untuk mendokumentasikan karya seni. Menurut Aris, membaca catatan atau notasi, dalam imaji pengrawit memiliki daya interpretasi untuk mengabstraksikan keseluruhan kesatuan wujud gending secara utuh (Setiawan, 2013). Setiap waktu, notasi untuk penulisan kendang Sunda mengalami perubahan sesuai dengan kreativitas yang dilakukan oleh para seniman akademisi. Dalam karawitan Sunda, Rival Maudiantana telah membahas tentang perubahan notasi kendang dalam setiap waktunya. Kesimpulannya bahwa notasi kendang dalam karawitan Sunda telah mengalami pergantian dalam setiap waktu sampai dengan sekarang (Maudiantana, 2015).

Notasi kendang yang digunakan di ISBI Bandung pada akhir-akhir ini terdapat dua yaitu notasi Pasunanda dan notasi yang dibuat oleh Lili Suparli. Menurut Sunarto, Pasunanda diambil dari nama para tokoh karawitan Sunda sebagai penyusun 
keberadaan notasi ini yaitu Pa singkatan dari Pandi, Su singkatan dari Suaman, Nand singkatan dari Nandang dan A singkatan dari Atik. Notasi ini digunakan cukup lama di ISBI Bandung terutama semasa STSI Bandung (Saepudin, 2015)(Sunarto, 2009). Adapun notasi terbaru yang dipakai adalah notasi hasil buatan Lili Suparli yang digunakan sejak tahun 2008-an di ISBI Bandung (Sunarto, 2015).

Notasi yang digunakan dalam perancangan ini adalah notasi Pasunanda. Alasannya adalah penulis lebih familier dengan notasi tersebut dan telah diajarkan oleh penulis di Jurusan Karawitan, ISI Yogyakarta selama kurang lebih dua belas tahun. Artinya, notasi Pasunanda masih berlaku bagi para mahasiswa sampai dengan sekarang. Adapun notasi hasil gubahan Lili Suparli akan menjadi pertimbangan di kemudian hari dalam perancangan penelitian selanjutnya agar kedua notasi dapat berjalan simultan mengisi kekosongan teknik penulisan notasi music Sunda.

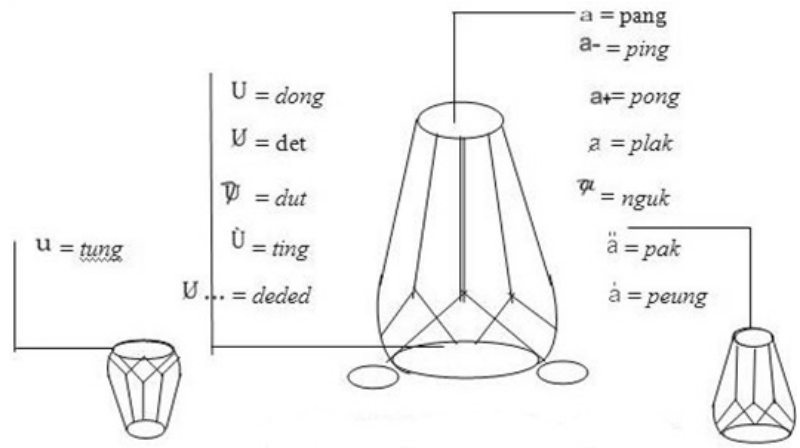

Gambar 1. Produksi suara kendang Sunda.

\begin{tabular}{|c|c|}
\hline $\begin{array}{l}\text { Kendang Indung: } \\
\text { Bagian Gedug } \\
\mathrm{U}=\text { dong } \\
U=\text { det } \\
\dot{\mathrm{U}}=\text { ting } \\
\mathrm{U} \ldots=\text { deded } \\
\overline{\mathrm{U}}=\text { dut } \\
\text { Bagian Kempyang } \\
\mathrm{a}=\text { pang } \\
\boldsymbol{a}=\text { plak } \\
\mathrm{a}==\text { ping } \\
\mathrm{a}+=\text { pong } \\
\not t=n g u k\end{array}$ & $\begin{array}{l}\text { b. Kendang Kulanter: } \\
\text { 1. Bagian Kutiplak } \\
\qquad a ̈=\text { pak } \\
\qquad \begin{array}{l}\dot{a}=\text { peung } \\
\text { 2. Bagian Katipung } \\
u=\text { tung }\end{array}\end{array}$ \\
\hline
\end{tabular}

Gambar 2. Notasi kendang Sunda.
Notasi Pasunanda digunakan untuk menulis notasi kendang Sunda baik kendang Ketuk Tilu, Jaipongan, Kiliningan, Pencak Silat, Keurseus, dan Degung. Notasi ini sudah cukup lama digunakan oleh Perguruan Tingi Seni di Bandung sejak zaman ASTI dan STSI sampai dengan tahun 2008-an. Notasi ini digunakan pula oleh penulis untuk memberikan kuliah teori dan praktik karawitan Sunda di ISI Yogyakarta. Notasi ini menggunakan tiga simbol huruf antara lain a, U, dan u (Gambar 1 dan 2).

Keterangan: Lambang di atas garis, menunjukkan tangan atas yakni tangan yang memukul bagian kumpyang dan kutiplak, sedangkan lambang di bawah garis menunjukkan tangan yang memukul bagian gedug dan katipung yakni tangan bagian bawah atau bidang muka besar bagian bawah (Saepudin, 2015).

\section{DaminatilaFont sebagai Sistem Penulisan Notasi yang Efektif}

Perkembangan teknologi saat ini sangat dirasakan manfaatnya dalam kehidupan manusia. Dalam media informasi, pemanfaatan kemajuan teknologi dapat dilakukan dengan metode-metode yang memanfaatkan multimedia (Maulana, Kusno, Studi, Informatika, \& Ahmad, n.d.). Secara umum peran teknologi dapat menggantikan peran manusia, memperkuat peran manusia, dan merestrukturisasi terhadap peran manusia (Fatmawati, n.d.). Teknologi membawa manusia melihat dunia luar lebih jauh, membuka wawasan berpikir dan membangun sebuah kreativitas untuk membuat hal-hal baru (Putu, Sanjaya, Adi, Kadek, \& Rusjayanthi, 2016). Maka, para seniman dan praktisi seni berusaha merespon kehadiran teknologi ini. Banyak para musisi atau komposer menggunakan program komputer sebagai tempat bekerja untuk mewujudkan ide-ide atau kreativitas yang dimilikinya (Wahyu Widodo, 2006). Khusus dalam dunia pendidikan dan pembelajaran, peranan media juga tidak bisa diabaikan. Dengan pesatnya perkembangan teknologi, kini proses pembelajaran dengan metode tradisional dapat diimplementasikan pada suatu media pembelajaran berbasis multimedia (Ariana \& Fajaraditya, 2015). 
DaminatilaFont adalah sistem penulisan notasi kendang dan gamelan Sunda yang merespon kehadiran teknologi yaitu dengan komputerisasi/ multimedia yang dibuat lebih mudah dan efektif. Mudah artinya penulisannya gampang dilakukan karena simbol notasi tidak dibuat secara manual, menggunakan simbol yang telah disediakan, dan pengerjaannya cukup satu kali ketikan saja. Efektif artinya waktu pengerjaan penotasian dilakukan dengan cepat, tidak memakan waktu lama karena pengerjaannya hanya satu kali proses pengetikan.

Penulis memberi nama program font ini DaminatilaFont. DaminatilaFont adalah sebuah wadah penulisan notasi kendang Sunda dan notasi daminatila yang dapat digunakan secara efektif untuk penulisan notasi terutama bagi para mahasiswa dan dosen di berbagai Perguruan Tinggi Seni di Indonesia. DaminatilaFont memiliki kelebihan jika dibandingkan dengan sistem penulisan notasi sebelumnya, antara lain: Pertama, proses pengerjaan DaminatilaFont sangat mudah dan sederhana. Cara menggunakannya cukup meng-copy saja. Kedua, DaminatilaFont dirancang lebih komplet yakni berguna tidak hanya untuk notasi kendang, akan tetapi bisa digunakan pula untuk penulisan notasi daminatila sebagai notasi gamelan dalam karawitan Sunda. Ketiga, DaminatilaFont tidak hanya memuat nada pokok yang berurutan seperti da (1), mi (2), na (3), ti (4), la (5), akan tetapi sudah dilengkapi pula dengan notasi sisipan Sunda seperti di (1-), leu (5+), meu (2+), ni (3-), deu (2+), dan lain-lain. Hal ini dilakukan untuk mengadopsi lagu-lagu yang memiliki nada miring (minir) dari nada pokok mengingat di dalam karawitan Sunda memiliki lima laras yaitu laras degung, salendro, madenda, mandalungan/mataraman, dan pelog (Saepudin, 2015a). Menurut Stefanus, adanya urutan nada merupakan pengaruh dari perkembangan matematika formal terhadap penamaan laras beserta representasinya dengan mengurutkan laras (nada) dari nada rendah ke nada tinggi (Osada, 2015). Titi laras dalam hal ini memegang peranan yang penting, sebab dengan titilaras dapat mencatat, mempelajari, dan menyimpan lagu yang sudah dinotasikan untuk dapat dipelajari dari generasi ke generasi (Suparli, Arini, \& Supriadi, 2015).
DaminatilaFont dapat mengakomodasi seluruh kebutuhan bagi penulisan notasi kendang Sunda terutama untuk merespon perkembangan dan perubahan tepak kendang dan instrumennya dalam karawitan Sunda (Saepudin, 2015c). DaminatilaFont dilengkapi notasi kendang dengan jumlah sumber bunyi diperbanyak seperti untuk kulanter katipung jumlahnya 5, untuk kulanter kutiplak jumlahnya 5, ditambah untuk kentrung jumlahnya 1. Adapun mengenai pelarasan kendang telah dibahas oleh Lalan Ramlan dalam tulisannya berjudul "Jaipongan: Genre Tari Generasi Ketiga" periksa (Ramlan, 2013).

DaminatilaFont dilengkapi juga dengan penulisan bentuk gending Sunda (seperti bentuk gurudugan,ayak-ayakan, rerenggongan, lenyepan, lalamba), dan embat yang digunakan (embat kering tilu, kering dua, sawilet, dua wilet, opat wilet) (Suparli, 2010: 65-90; Irawan, 2014). Inilah kelebihan DaminatilaFont jika dibandingkan dengan sistem penulisan notasi kendang dan gamelan Sunda sebelumnya.

\section{Proses Perancangan DaminatilaFont}

Dalam pembuatan font notasi kendang DaminatilaFont, dilakukan melalui beberapa tahapan percobaan sesuai dengan perjalanan waktu dan kebutuhan di lapangan. Adapun tahap-tahapan percobaan yang dilakukan adalah sebagai berikut:

\section{Tahap Pertama}

Pada tahap pertama, notasi kendang disusun menyesuaikan dengan angka atau huruf yang tersedia dalam keyboard (papan kunci) laptop/ komputer. Komputer yang dimaksud adalah komputer digital yang biasa digunakan dalam kehidupan sehari-hari (Saputra \& Sriwijaya, 2009). Artinya, segala angka dan huruf yang digunakan untuk menuliskan notasi kendang dan gamelan mengikuti apa adanya dari keyboard pada laptop atau komputer yang telah tersedia di pasaran. Proses seperti ini paling banyak dilakukan oleh para sarjana S-1, S-2, maupun S-3 terutama yang berhubungan dengan penotasian kendang Sunda. Dalam penulisan ini, karakter huruf yang digunakan biasanya Times New Roman dengan 
font 12 atau Bookman Old Style. Contoh hasil penotasian lihat gambar 3 .

Sekilas, notasi gambar 3 mudah untuk dibaca sehingga tidak ada permasalahan di dalamnya. Akan tetapi, proses pengerjaan notasi di atas sangat sulit dilakukan mengingat seluruh notasi ditulis secara manual, artinya mengandalkan karakter huruf yang telah tersedia di dalam laptop atau program komputer. Hal yang paling menyulitkan adalah untuk menulis harga notasi misalnya harga not satu ketukan, setengah ketuk, seperempat ketuk, atau seperdelapan ketuk. Untuk menulis harga notasi tersebut harus dibuat secara manual mengambil dari insert, shapes, dan selanjutnya mengambil garis. Garis yang sudah diambil kemudian dipotong-potong sesuai dengan kebutuhan harga not. Pengerjaan seperti ini tidak bisa dilakukan hanya satu kali pengerjaan, akan tetapi dilakukan secara berulang-ulang sampai ukuran garis yang dibutuhkan sesuai dengan harga not. Tentunya pekerjaan seperti ini memerlukan waktu yang lama dan tidak efektif dalam pengerjaannya.

Selain harga notasi, kesulitan lainnya adalah tidak tersedianya nada yang tinggi dan rendah berupa tanda titik di atas dan di bawah angka,

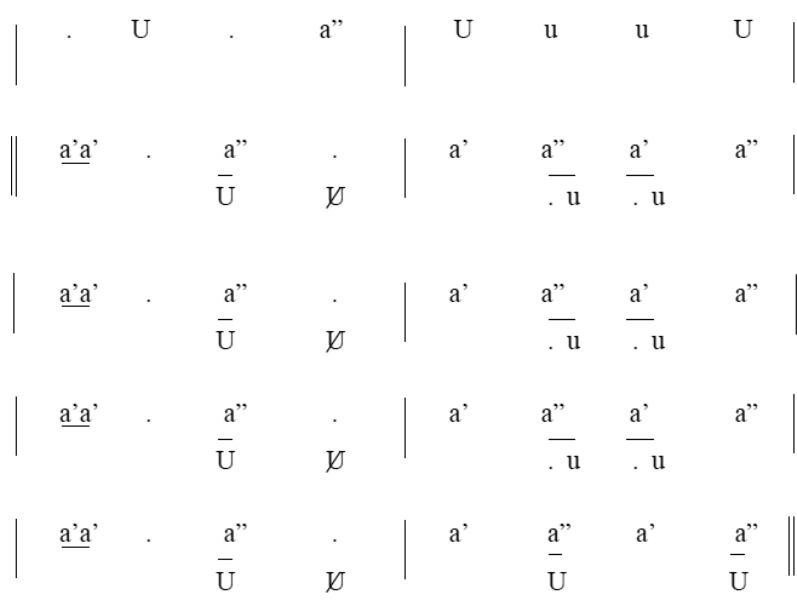

Gambar 3. Penotasian kendang Sunda.

(Sumber: Saepudin, 2012a)

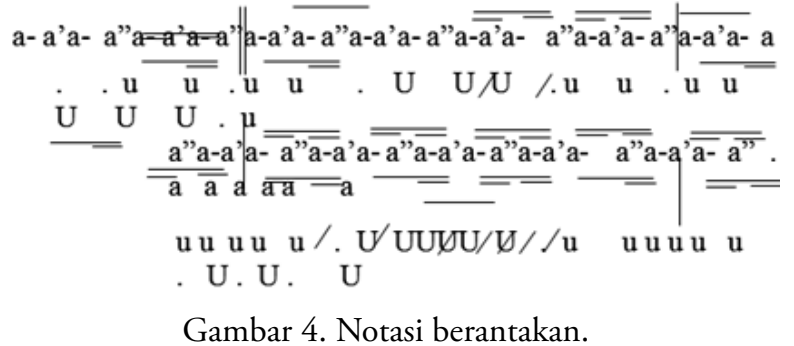

karena notasi angka hanya apa adanya yang terdapat di dalam keyboard laptop/komputer. Dampaknya, notasi nada rendah dan nada tinggi (titik di bawah dan titik di atas) tidak terwakili dalam notasi sehingga nadanya hanya nada normal/ tengah saja. Maka notasi yang sudah ditulis tidak dapat mewakili suara nada atau vokal nada tinggi dan rendah karena tidak ada tanda titik bawah atau atas di dalam not angka. Adapun jika dibutuhkan, maka diberi titik secara manual dengan ballpoint setelah diprint terlebih dahulu. Tentunya cara seperti ini sangat tidak efektif.

Permasalahan yang lebih rumit lagi adalah ketika notasi tersebut dicopy atau dipindahkan dalam halaman yang berbeda. Ketika notasi di atas dicopy ke dalam halaman yang berbeda, yang sering terjadi adalah susunan notasi menjadi berantakan, dapat berubah angka, huruf, atau harga notnya. Harga not biasanya berceceran di mana-mana karena garis-garis yang ada dibuat secara manual (Gambar 4).

Gambar 4 memperlihatkan adanya garis notasi kendang yang berantakan, ke luar dari tempat yang semestinya. Ini akibat dari penulisan notasi yang bersifat manual sehingga hasilnya menjadi tidak beraturan jika dipindahkan atau dicopy. Berdasarkan pengalaman tersebut, maka penulis mencoba mencari alternatif kedua untuk membuat penulisan notasi secara efektif.

\section{Tahap Kedua}

Oleh karena sulitnya teknis menotasikan kendang Sunda serta prosesnya memerlukan waktu yang lama seperti telah dijelaskan di depan, penulis mencari alternatif lain dalam teknis penotasian kendang Sunda yaitu membuat notasi kendang dengan sistem mengcopy. Cara yang dilakukan adalah membuat babon notasi pokok terlebih dahulu secara manual dengan menggunakan garis notasi berasal dari keyboard laptop atau komputer melalui insert, shapes, lalu pilih garis. Garis yang sudah diambil kemudian dipotongpotong dan dicopy sesuai dengan kebutuhan dalam penotasian. Langkah yang dilakukan adalah membuat garis notasi terlebih dahulu dengan harga ritmis seperempat dalam seluruh matranya. Ritmis yang sudah jadi yang memiliki harga seperempat, 
kemudian dijadikan babon/induk/pokok notasi yang bisa dicopy untuk beberapa halaman. Setelah dicopy sesuai kebutuhan, barulah menulis notasi kendang sesuai dengan melodi yang dibutuhkan dan ritmis yang ada di dalam notasi yang harga notnya $1 / 4$. Adapun jika ada harga not atau ritmis yang berbeda dari babon pokok misalnya harga not $1,1 / 2,1 / 8$, maka yang dilakukan adalah menghilangkan ritmis yang sudah jadi satu persatu (Gambar 5).

Setelah dilakukan uji coba dalam beberapa kali penulisan notasi kendang, cara kedua ini sudah lebih baik dibandingkan dengan cara yang pertama karena ritmisnya sudah ada, tidak perlu manual lagi membuat sendiri satu demi satu. Hanya saja dalam pengerjaannya tetap tidak efektif karena memerlukan waktu yang lama meskipun hanya untuk menulis notasi satu lembar saja. Hal ini disebabkan menulis notasi kendang menjadi dua kali pengerjaan yakni: pertama, menuliskan atau mengcopy notasi sesuai dengan ritmis yang ada. Kedua, menghilangkan harga dari ritmis pokok yang dijadikan sampel yang tidak sesuai dengan ritmis yang diinginkan. Artinya, tetap saja bahwa cara yang demikian tidak efektif dalam mengerjakan notasi kendang Sunda. Maka dari itu, cara kerja penulisan notasi dengan cara kedua tersebut tidak efektif jika digunakan dalam penotasian. Atas dasar pertimbangan tersebut, penulis merancang kembali notasi teknik penulisan notasi kendang Sunda dengan tahap ketiga.

\section{Tahap Ketiga}

Tahap ketiga ini, penulis mencoba membuat notasi kendang Sunda dengan memanfaatkan font yang telah ada dan berkembang dalam karawitan Jawa yakni Font Kepatihan atau KepatihanFro. Font Kepatihan adalah font untuk menuliskan

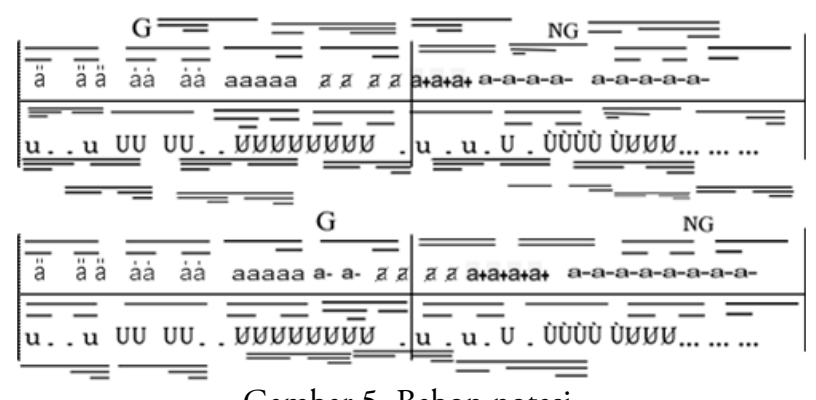

Gambar 5. Babon notasi. notasi Jawa (notasi kepatihan) yang dibuat oleh Matthew Arciniega dari Amerika (Arciniega, 2010). Pada tahap ini, penulis merancang terlebih dahulu simbol-simbol notasi kendang Sunda yang dibutuhkan, kemudian dicari ruang dalam font kepatihan yang bisa ditempati untuk notasi kendang Sunda, lalu diselipkan di dalam font kepatihan sehingga dapat digunakan untuk menulis kendang Sunda.

Cara ketiga di atas dirasa lebih mudah dan efektif karena menulis notasi kendang tidak manual lagi, tetapi sudah tersedia secara langsung dengan mengikuti langkah-langkah yang telah disusun sesuai petunjuk penulisan. Nama fontnya adalah Anggit Sunda5. Adapun proses penulisannya sebagai berikut: Buka program Microsoft Word 2010, lalu cari control panel kemudian klik font. Langkah selanjutnya memasukkan font Anggit Sunda5 ke

Tabel 1. Teknik penulisan notasi kendang.

\begin{tabular}{cc}
\hline Bunyi Kendang & Klik Papan Kunci \\
\hline dong & $\mathrm{C}$ \\
det & $\mathrm{V}$ \\
ting & $\mathrm{B}$ \\
deded & $\mathrm{N}$ \\
deded & $\mathrm{H}$ \\
tung & $\mathrm{M}$ \\
pang & $\mathrm{I}$ \\
pong & $\mathrm{J}$ \\
ping & $\mathrm{K}$ \\
phak & $\mathrm{L}$ \\
peung & $\mathrm{O}$ \\
pak & $\mathrm{P}$ \\
\hline
\end{tabular}
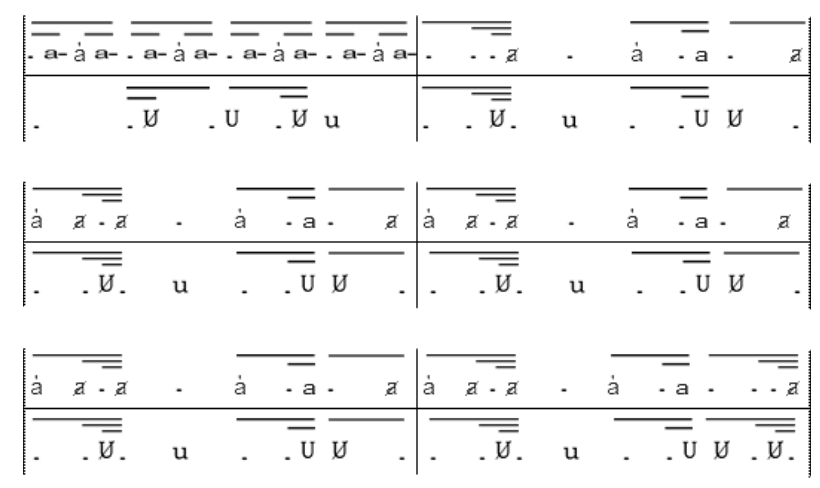

Gambar 6. Contoh hasil penulisan notasi.

(Sumber: Saepudin, 2012b) 
dalam Font, lalu copy. Setelah itu, klik caps lock, barulah dapat menuliskan notasi kendang Sunda. Sebagai contoh, bunyi dong dengan klik C, bunyi det dengan klik $\mathrm{V}$, dan sebagainya (Tabel 1).

Cara penulisan pada gambar 6, telah memberikan kontribusi besar bagi penulisan notasi kendang Sunda karena lebih praktis dan lebih mudah jika dibandingkan dengan cara pertama dan kedua. Hanya saja kelemahannya adalah notasi kendang tersebut kadang kadang terjadi perubahan warna terutama dalam garis notasi. Hal yang terjadi adalah sering muncul garis notasi warna biru yang bukan notasi sebenarnya ketika dijadikan gambar JPG sehingga dapat mengganggu notasi yang pokok. Selain itu, notasi ini belum dilengkapi dengan notasi angka yang dibutuhkan untuk penulisan notasi daminatila. Kelemahan lainnya adalah Hak Kekayaan Intelektual (HKI) dari teknik penulisan notasi ini tidak bisa dipatenkan karena pembuatan notasi berdasarkan font yang telah ada yakni font kepatihan. Proses penulisan notasi ini digunakan hanya untuk kepentingan sendiri, tidak untuk dipublikasikan kepada pengguna lainnya. Oleh karena itu, penulisan notasi di atas masih perlu dibenahi dari berbagai aspek agar hasil penulisannya dapat mudah dan efektif serta legalitas kepemilikannya dapat dimiliki. Atas dasar inilah, maka dibutuhkan perancangan kembali sistem penotasian kendang Sunda yang lebih komplit, mudah, dan efektif sebagai hasil karya dan kepemilikan sendiri. Artinya, tahap ketiga di atas sebagai sumber inspirasi untuk membuat sistem penotasian berikutnya yang lebih baik dan komplit agar dapat mewakili seluruh penotasian dalam karawitan Sunda baik kendang maupun gamelan.

\section{Tahap Keempat}

Tahap keempat ini sebagai hasil penyempurnaan dari tahapan pertama sampai tahapan ketiga. Jika dibandingkan dengan cara sebelumnya, maka tahapan keempat ini lebih komplet dan cocok untuk penulisan notasi kendang dan gamelan dalam karawitan Sunda. Adapun penyempurnaan yang telah dilakukan dalam tahap keempat antara lain: (1) Notasi dibuat dengan font sendiri, tidak menggunakan font yang lain seperti pada tahapan sebelumnya; (2) Notasi pada tahapan keempat lebih lengkap karena ditambah untuk notasi daminatila terutama untuk nada tinggi dan nada rendah; (3) Sistem penulisan notasi telah dilengkapi pula dengan simbol-simbol baru yang menyesuaikan perkembangan kendang jaipong saat ini terutama di Jawa Barat yakni memiliki banyak kendang, banyak kulanter dan kendang kentrung sehingga notasinya semakin banyak dan semakin kompleks; (4) Simbol gamelan telah dilengkapi dengan simbol nada tambahan eu (+) dan $i(-)$ yang difungsikan untuk penulisan nada-nada sisipan; (5) Selain dilengkapi dengan nada-nada sisipan, sistem penulisan notasi ini dilengkapi pula dengan bentuk gending dan embat yang terdapat dalam karawitan Sunda. Hal ini penting untuk mempermudah pembaca dalam menafsir gending yang disajikan; (6) Sistem penulisan notasi tahap keempat ini diberi nama DaminatilaFont.

DaminatilaFont memiliki simbol lebih komplit dari simbol-simbol yang terdapat pada tahap pertama sampai ketiga (Tabel 2 sampai 9).

Tabel 2. Penulisan simbol embat.

\begin{tabular}{ccc}
\hline Nama & DaminatilaFont & Key \\
\hline gurudugan & $\mathrm{G}$ & $\mathrm{A}$ \\
ayak-ayakan & $\mathrm{A}$ & $\mathrm{S}$ \\
rerenggongan & $\mathrm{R}$ & $\mathrm{D}$ \\
lenyepan & $\mathrm{Le}$ & $\mathrm{F}$ \\
lalamba & $\mathrm{La}$ & $\mathrm{G}$ \\
kering tilu & $\mathrm{III}$ & $\mathrm{Y}$ \\
kering dua & $\mathrm{II}$ & $\mathrm{U}$ \\
sawilet & $\mathrm{I}$ & $\mathrm{I}$ \\
dua wilet & $\mathrm{II}$ & $\mathrm{O}$ \\
opat wilet & $\mathrm{IV}$ & $\mathrm{P}$ \\
\hline
\end{tabular}

Tabel 3. Penulisan simbol kolotomik.

\begin{tabular}{ccc}
\hline Nama & DaminatilaFont & Key \\
\hline kenong & $\mathrm{N}$ & $=$ \\
kempul & $\mathrm{U}$ & - \\
gong & $\mathrm{O}$ & 0 \\
kempyang & - & - \\
ketuk & + & + \\
get & $\wedge$ & {[} \\
cer & $\mathrm{v}$ & ] \\
\hline
\end{tabular}


Tabel 4. Penulisan simbol tanda ulang.

\begin{tabular}{ccc}
\hline Nama & DaminatilaFont & Key \\
\hline matra & $\mid$ & 8 \\
tanda ulang & $\|$ & $*$ \\
pengulangan A & {[} & ( \\
pengulangan & ] & ) \\
pengulangan B & {[} & \{ \\
\hline
\end{tabular}

Tabel 5. Penulisan simbol notasi Daminatila.

\begin{tabular}{ccc}
\hline Nama & DaminatilaFont & Key \\
\hline da & 1 & 1 \\
mi & 2 & 2 \\
na & 3 & 3 \\
ti & 4 & 4 \\
la & 5 & 5 \\
eu & + & 6 \\
i & - & 7 \\
da alit & 1 & $!$ \\
mi alit & 2 & ' \\
na alit & 3 & $\#$ \\
ti alit & 4 & $\$$ \\
la alit & 5 & $\%$ \\
2 oktaf bawah &.. & $\wedge$ \\
da ageung & 1. & $\mathrm{q}$ \\
mi ageung & 2. & $\mathrm{w}$ \\
na ageung & 3. & $\mathrm{e}$ \\
ti ageung & 4. & $\mathrm{r}$ \\
la ageung & 5. & $\mathrm{t}$ \\
2 oktaf atas & “ & $\&$ \\
\hline
\end{tabular}

Tabel 6. Penulisan notasi kendang bagian kumpyang.

\begin{tabular}{ccc}
\hline Nama & DaminatilaFont & Key \\
\hline ping & $\mathrm{a}-$ & $\mathrm{P}$ \\
pang & $\mathrm{a}$ & $\mathrm{O}$ \\
phak & $\mathrm{a} /$ & $\mathrm{I}$ \\
pong & $\mathrm{a}+$ & $\mathrm{U}$ \\
nguk & $\mathrm{aj}$ & $\mathrm{y}+\mathrm{o}$ \\
peung & $\mathrm{a}$ & $\mathrm{k}$ \\
peung1 & $\mathrm{a} 1$ & $\mathrm{Q}+\mathrm{k}$ \\
peung2 & $\mathrm{a} 2$ & $\mathrm{~W}+\mathrm{k}$ \\
peung3 & $\mathrm{a}$ '3 & $\mathrm{E}+\mathrm{k}$ \\
peung4 & $\mathrm{a} ' 4$ & $\mathrm{R}+\mathrm{k}$ \\
peung5 & $\mathrm{a}$ '5 & $\mathrm{T}+\mathrm{k}$ \\
\hline
\end{tabular}

Tabel 7. Penulisan notasi kendang bagian kutiplak.

\begin{tabular}{ccc}
\hline Nama & DaminatilaFont & Key \\
\hline pak & a" & $\mathrm{L}$ \\
pak1 & $\mathrm{a} " 1$ & $\mathrm{Q}+\mathrm{l}$ \\
pak2 & $\mathrm{a}^{\prime 2}$ & $\mathrm{~W}+\mathrm{l}$ \\
pak3 & $\mathrm{a}^{\prime 3}$ & $\mathrm{E}+\mathrm{l}$ \\
pak4 & $\mathrm{a}$ 4 & $\mathrm{R}+\mathrm{l}$ \\
pak5 & $\mathrm{a}^{\wedge}$ & $\mathrm{T}+\mathrm{l}$ \\
plak & $\mathrm{a}^{\wedge}$ & $\mathrm{j}$ \\
plak1 & $\mathrm{a}^{\wedge} 1$ & $\mathrm{Q}+\mathrm{j}$ \\
plak2 & $\mathrm{a}^{\wedge} 2$ & $\mathrm{~W}+\mathrm{j}$ \\
plak3 & $\mathrm{a}^{\wedge} 3$ & $\mathrm{E}+\mathrm{j}$ \\
plak4 & $\mathrm{a}^{\wedge} 4$ & $\mathrm{R}+\mathrm{j}$ \\
plak5 & $\mathrm{a}^{\wedge} 5$ & $\mathrm{~T}+\mathrm{j}$ \\
\hline
\end{tabular}

Tabel 8. Penulisan notasi kendang bagian gedug.

\begin{tabular}{ccc}
\hline Nama & DaminatilaFont & Key \\
\hline dong & $\mathrm{U}$ & $\mathrm{V}$ \\
$\operatorname{det}$ & $\mathrm{U} /$ & $\mathrm{B}$ \\
$\operatorname{dedet}$ & $\mathrm{U} / .$. & $\mathrm{N}$ \\
ting & $\mathrm{U}$. & $\mathrm{M}$ \\
dut & $\mathrm{Dj}$ & $\mathrm{y}+\mathrm{v}$ \\
dedet & $\ldots$ & $\mathrm{H}$ \\
\hline
\end{tabular}

Tabel 9. Penulisan notasi kendang bagian katipung.

\begin{tabular}{ccc}
\hline Nama & DaminatilaFont & Key \\
\hline tung & $\mathrm{u}$ & $\mathrm{g}$ \\
tung1 & $\mathrm{u} 1$ & $\mathrm{Q}+\mathrm{g}$ \\
tung2 & $\mathrm{u} 2$ & $\mathrm{~W}+\mathrm{g}$ \\
tung3 & $\mathrm{u} 3$ & $\mathrm{E}+\mathrm{g}$ \\
tung4 & $\mathrm{u} 4$ & $\mathrm{R}+\mathrm{g}$ \\
tung5 & $\mathrm{u} 5$ & $\mathrm{~T}+\mathrm{g}$ \\
trung & $\mathrm{Tr}$ & $\mathrm{F}$ \\
\hline
\end{tabular}

\section{Proses Pembuatan DaminatilaFont}

Alat yang digunakan untuk membuat sistem penulisan notasi DaminatilaFont terdiri dari tiga komponen besar yakni hardware, software, dan font acuan. Hardware yang digunakan adalah laptop ASUS X453M, dekstop, dan printer scanner merk cannon seri MG2500. Laptop dan dekstop digunakan untuk pengolahan data dan aplikasi 
notasi, sedangkan scanner digunakan untuk menscan gambar notasi kendang hasil rancangan. Software yang digunakan adalah High-Logic Font Creator 6.5 dan Corel DRAWX7, sedangkan font acuan yang digunakan dasar pembuatan adalah Kepatihan Pro, Anggit Sunda5, Consolas, dan Courier New. Kepatihan Pro digunakan sebagai rujukan pokok penulisan notasi, Anggit Sunda5 digunakan sebagai contoh awal penotasian, sedangkan Courier New digunakan untuk karakter huruf penulisan notasi.

\section{Tahap-Tahap Pembuatan DaminatilaFont}

Pembuatan DaminatilaFont memiliki beberapa tahapan pengerjaan sesuai dengan kebutuhan dan perkembangan di lapangan. Adapun tahapannya sebagai berikut: Tahap pertama, merancang simbol dan karakter huruf. Simbol dan karakter huruf untuk notasi dirancang sesuai dengan kebutuhan dan karakter notasi yang berlaku dalam karawitan Sunda. Seluruh simbol yang sudah terbentuk kemudian dipilih dan dipilah agar sesuai dengan kebutuhan di lapangan yakni kebutuhan akan notasi bagi penulisan simbol kendang Sunda dan juga notasi daminatila. Sebelum melakukan pemilihan simbol, penulis melakukan observasi terlebih dahulu ke lapangan yakni ke ISBI Bandung sebagai pusatnya Perguruan Tinggi Seni di Sunda yang biasa menggunakan notasi kendang dalam perkuliahannya.

Berdasarkan hasil observasi, studi pustaka dan wawancara kepada para narasumber terutama pengajar kendang Sunda, diperoleh data bahwa di ISBI Bandung terdapat dua simbol notasi kendang yakni simbol yang digunakan pada masa angkatan sebelum tahun 2008 dan angkatan setelah 2008 sampai dangan sekarang. Simbol sebelum tahun 2008 menggunakan simbol notasi Pasunanda yang sering digunakan dalam mempelajari kendang Sunda. Adapun simbol yang digunakan para mahasiswa dan dosen setelah tahun 2008 menggunakan simbol yang dibuat oleh Lili Suparli (Suparli, 2010) dan belum diberi nama. Perlu diketahui bahwa meskipun kedua simbol notasi kendang yang ada di ISBI Bandung telah digunakan sejak lama, namun cara penulisannya masih manual yakni dengan menggunakan sistem copy paste. Simbol terbaru hasil buatan Lili Suparli telah ada, namun penulisannya masih manual. Hal ini dapat ilihat dari hasil tulisan para mahasiswa S-1 yang telah menempuh Ujian. Oleh karena itu, pembuatan sistem penulisan notasi yang penulis rancang ini bersiat orsinalitas karena belum ada yang melakukannya. Dengan demikian, selesainya DaminatilaFont ini akan bermanfat bagi para akademisi yang memerlukan analisis musikal maupun pendokumentasian motif-motif tepak kendang Jaipongan.

Melihat fakta di atas bahwa terdapat dua sistem penulisan notasi, maka dalam perancangan ini menggunakan notasi yang lama yakni notasi Pasunanda dengan pertimbangan bahwa notasi tersebut telah lebih lama digunakan oleh para akademisi untuk menulis notasi kendang. Notasi Pasunanda diajarkan juga di Jurusan Karawitan ISI Yogakarta. Adapun untuk mewadahi sistem penulisan dengan simbol yang baru, akan dilakukan pada penelitian selanjutnya agar dua generasi pengendang dan akademisi dapat terwakili.

Tahap kedua adalah membuat pemetaan karakter/simbol dalam keyboard laptop/komputer dengan pertimbangan pengelompokkan simbol melalui kelompok kolotomis, angka, kendang, dan singkatan. Membuat pemetaan simbol harus diperhitungkan agar efektif, efisien, serta tidak membingungkan dalam penulisannya. Oleh karena itu, simbol-simbol yang telah ada disesuaikan dengan kebutuhan penotasian serta dipetakan sesuai dengan keybord yang telah ada pada laptop atau komputer.

Tahap ketiga adalah membuat gambar simbol secara manual. Setelah diperoleh tentang pengelompokkan simbol-simbol notasi, kemudian simbol-simbol notasi dibuat gambar terlebih dahulu dengan pena/pensil di dalam kertas sebagai modal dasar untuk pembuatan simbol di laptop/komputer. Pembuatan gambar disesuaikan dengan karakter tanda yang dibuat sendiri maupun menyesuaikan dengan simbol yang telah tersedia di komputer. Adapun simbol huruf menyesuaikan dengan simbol notasi Pasunanda. Gambar simbol dalam kertas dijadikan dasar/basic notasi untuk dapat dikembangkan dan discan. 
Langkah selanjutnya adalah scan gambar, lalu edit secara digital. Setelah gambar simbol terwujud dalam kertas, langkah selanjutnya adalah melakukan scan gambar. Gambar simbol semuanya di-scan menggunakan scanner, kemudian diedit secara digital menggunakan CorelDRAW $X 7$. Dalam program ini digunakan fasilitas trace untuk mendapatkan garis vector dan pen tool untuk membuat garis vector. Proses pengeditan dilakukan berulang-ulang untuk mendapatkan hasil yang memuaskan dengan shape tool atau edit kurva.

Jika gambar sudah diedit dalam CorelDraw X7 dan cocok untuk notasi kendang Sunda, langkah selanjutnya mengeksport seluruh gambar simbol notasi ke dalam format PNG (save as type PNG). Kemudian jalankan font creator (HLFC6.5) new file (nama font baru) (hal ini untuk menentukan nama dan kategori/klasifikasi font). Setelah itu klik, format lalu setting (tentukan metadata), atur format dasar font yang akan dibuat (ukuran posisi global). Langkah selanjutnya menentukan mapping, kemudian melakukan import gambar PNG ke dalam font creator untuk diselaraskan ukuran masing karakter/simbol atau mengatur orientasi tiap-tiap karakter. Sebagai langkah terakhir adalah melakukan test font yang sudah dibuat. Jika hasil test font kurang tepat, dilakukan lagi pengulangan untuk mengatur orientasi tiaptiap karakter sampai karater huruf yang diinginkan dapat tercapai (Gambar 12).

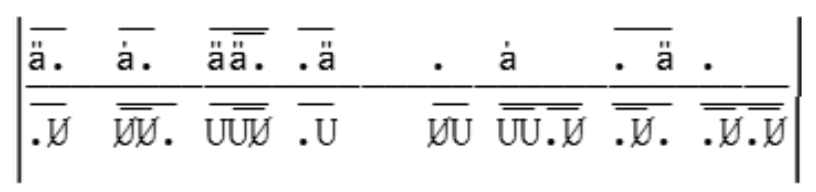

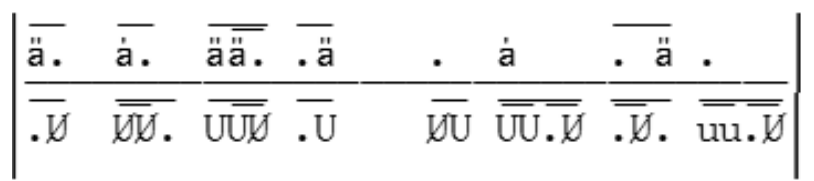

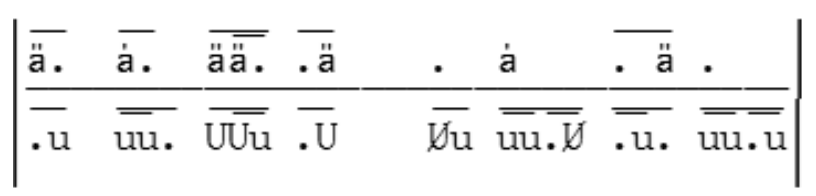

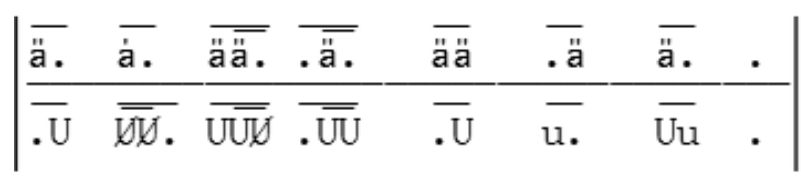
Gambar 12. Hasil penulisan notasi DaminatilaFont.

\section{Penutup}

Berdasarkan penjelasan di atas bahwa telah terwujud hasil perancangan DaminatilaFont sebagai media untuk menulis notasi kendang Sunda khususnya kendang jaipongan dan notasi Daminatila berbasis komputer. DaminatilaFont merupakan solusi terbaik untuk mengatasi permasalahan penulisan notasi dalam karawitan Sunda. Berdasarkan hasil ujicoba dapat disimpulkan bahwa DaminatilaFont dapat mengakomodasi kebutuhan penulisan notasi Sunda serta dapat mempercepat penulisan notasi Sunda sehingga pengerjaanya dapat dengan mudah dan efisien.

\section{Kepustakaan}

Arciniega, M. (2010). Kepatihan Fro Font: Key Layout and Example. USA.

Ariana, A. A. G. B., \& Fajaraditya, I. N. A. (2015). Rancang Bangun Media Pembelajaran Alat Musik Gamelan Gong Kebyar Berbasis Android.Jurnal S@cies, 5(2), 63-68.

Arief, A. (2016). Pemanfaatan Program "Bata" Pada Pembelajaran Seni Musik Untuk Meningkatkan Pemahaman Notasi Balok Dan Notasi Angka Siswa. JPSD : Jurnal Pendidikan Sekolah Dasar, 2(1), 36-42.

Eka, Y. D. (2017). Pengaruh Kemampuan Membaca Notasi Terhadap Hasil Belajar Ekstrakurikuler Ansambel Pianika Di Smp Negeri 36 Semarang. Journal of Economic Education, 6(2), 9-13.

Gratia, P. S., Johar, A., \& Farady, F. (2015). Pembelajaran Notasi Musik Berbasis Teknologi Informasi dan Komunikasi (Studi Kasus Mata Pelajaran Seni Budaya dan Keterampilan Kelas 7 di SMPN 11 Kota Bengkulu. Jurnal Rekursif, 3(1), 37-43.

Hastuti, Khafi izh, dan Syarifzh, A. M. (2016). Identifikasi Fitur Melodi Dalam Musik Gamelan Berdasarkan Hubungan Asosiasi Antar-Notasi. In Seminar Nasional Sistem Informasi Indonesia, 1 Nopember 2016 (pp. 47-54).

Irawan, E. (2014). Karakter Musikal Lagu Gede Kepesindenan Karawitan Sunda. Resital Jurnal 
Seni Pertunjukan, 15(1), 18-31.

Julia. (2016). Sistem Notasi untuk Pembelajaran

Kecapi Indung. Ritme UPI Bandung, 2(1), 27-32.

Maudiantana, R. (2015). Ragam Penulisan Kendang dalam Karawitan Sunda. Skripsi Jurusan Karawitan ISBI Bandung.

Merriam, A. P. (1995). "Metode dan Teknik Penelitian dalam Etnomusikologi" .Supanggah (ed.) Etnomusikologi (1st ed., pp. 89-122). Yogyakarta: Yayasan Bentang Budaya.

Nettl, B. (1964). Theory And Method In Ethnomusicology. London: The Free Press of Glencoe, Collier-Macmilian Limited.

Novita, E., Syahrin, A., Pramana, Y., Rahmati, S., Rizki, I., \& Tri, J. (2018). Upaya Pelestarian Kesenian Rapa 'I Daboh Dengan Menggunakan Literatur Tertulis Dan Notasi Musik. Rambideun : Jurnal Pengabdian Kepada Masyarakat, 1(2), 7-11.

Osada, S. S. (2015). Etnomatematika dalam Titi Laras dan Irama Pada Karawitan Jawa. In Prosiding Seminar Nasional Etnomatnesia, Universitas Sanata Dharma Yogyakarta (pp. 475-481).

Putu, D., Sanjaya, A., Adi, I. K., Kadek, N., \& Rusjayanthi, D. (2016). Pengenalan Tradisi Budaya Bali melalui Aplikasi Game Explore Bali Berbasis Android, 7(3), 162-173. https:// doi.org/10.24843/LKJITI.2016.v07.i03.p04

Ramlan, L. (2013). Jaipongan : Genre Tari Generasi Ketiga dalam Perkembangan Seni Pertunjukan Tari Sunda, 14(1), 41-55.

Rusdiyantoro. (2011). Notasi Kepatihan: Kebertahanan, Perkembangan Dan Dampaknya Terhadap Kehidupan Karawitan. Program Pascasarjana, Institut Seni Indonesia, Surakarta.

Saepudin, A. (2012a). Praktik Karawitan Daerah Lain I Karawitan Sunda. Diktat Jurusan
Karawitan FSP ISI Yogyakarta.

Saepudin, A. (2012b). Tepak Kendang Jaipongan dalam Lagu Daun Pulus Keser Bojong. Selonding, 2(2), 187-210.

Saepudin, A. (2015). Laras, Surupan, dan Patet dalam Praktik Menabuh Gamelan Salendro. Resital Jurnal Seni Pertunjukan, 16(1), 52-64. https://doi.org/http://dx.doi.org/10.24821/ resital.v16i1.1274

Saepudin, A. (2015). Metode Pembelajaran Tepak Kendang Jaipongan (1st ed.). Yogyakarta: Badan Penerbit ISI Yogyakarta. Retrieved from http://digilib.isi.ac.id/id/eprint/2028

Saepudin, A. (2015). Perkembangan dan Perubahan Tepak Kendang Jaipongan Suwanda dalam Masyarakat Urban. Journal Of Urban Societys Arts, 2(1), 9-17.

Saputra, H., \& Sriwijaya, P. N. (2009). Kajian Tentang Komputer Kuantum Sebagai Pengganti Komputer Konvensional Di Masa Depan. Jurnal Generic, 4(2), 15-18.

Setiawan, A. (2013). Konfigurasi Karawitan Jawatimuran. Gelar Jurnal Seni Budaya, 11(1), $1-14$.

Sunarto. (2009). Tepak Kendang Jaipongan Suwanda. Program Pengkajian Seni, Minat Studi Musik Nusantara ISI Surakarta.

Sunarto. (2015). Kendang Sunda (1st ed.). Bandung: Sunan Ambu Press.

Suparli, L. (2010). Gamelan Pelog Slendro: Induk Teori Karawitan (1st ed.). Bandung: Sunan Ambu Press.

Suparli, L., Arini, D., \& Supriadi, D. (2015). Karakter Musik Etnik. Panggung Jurnal Seni Dan Budaya, 25(2), 177-188.

Wahyu Widodo, T. (2006). Komputer dan Pengetahuan Program Aplikasi Musik Komputer. Harmonia, Jurnal Pengetahuan Dan Pemikiran Seni, 7(2). 180 - 200 